\title{
Effect of irisin on metabolic and platelet functions in type 2 diabetic rats: role of soluble receptor of advanced glycation end products (sRAGE)
}

\author{
SherifW. Mansour ${ }^{1,2}$, Mai M. Hasan ${ }^{1}$, Hossam E. Salah ${ }^{3}$, Talal El-Deep ${ }^{1,4}$, Samia Hussein ${ }^{5^{*}}$ (1) and \\ Nanees F. El-Malkey'
}

\begin{abstract}
Background: Irisin is an adipomyokine with a promising potential for the treatment of metabolic disturbances and endothelial dysfunction. This study aimed to explore the effect of irisin on metabolic and platelet functions, and to explore the possible involvement of soluble receptor of advanced glycation end product (sRAGE) in the type 2 diabetes mellitus (T2DM) rat model. Thirty-three adult male albino rats were divided into three groups: normal control, vehicle-treated T2DM group, and irisin-treated T2DM. At the end of the study period, metabolic parameters, platelet count, mean platelet volume, platelet distribution width, plateletcrit, and serum sRAGE were determined.

Results: Irisin significantly improved platelet function and metabolic derangements induced by T2DM and significantly increased sRAGE. sRAGE was significantly negatively associated with platelet function parameters and some glucometabolic parameters. Additionally, mean platelet volume showed a significant predictive value for the change in serum sRAGE.

Conclusions: Irisin could have a protective role against diabetes-induced platelet dysfunction by increasing sRAGE levels, indicating the potential beneficial effects of SRAGE in the type 2 diabetic rat model.
\end{abstract}

Keywords: Diabetes, Irisin, Platelet, sRAGE, Hyperglycemia, Inflammation

\section{Background}

Type 2 diabetes mellitus (T2DM) is a serious, global metabolic health problem with a high prevalence and morbidity that is complicated by atherosclerosis and circulatory dysfunction [1]. The high incidence of thrombotic complications reported in T2DM patients is attributed to altered platelet morphology and function, since platelets have been found to be large and hyperactive with increased adhesion and aggregation [2].

\footnotetext{
*Correspondence: samiahussein82@hotmail.com

${ }^{5}$ Medical Biochemistry and Molecular Biology, Faculty of Medicine,

Zagazig University, Zagazig, Egypt

Full list of author information is available at the end of the article
}

Boström et al. [3] discovered irisin, which is a novel myokine that is secreted from exercised skeletal muscle cells by cleavage of the fibronectin type III domaincontaining protein 5 (FNDC5) via the activation of peroxisome proliferator-activated receptor $\gamma$ (PPAR $\gamma$ ) co-activator-1 $\alpha$ (PGC-1 $\alpha)$. Recent studies have shown that irisin is also secreted from white adipose tissue and may regulate several physiological and metabolic pathways that protect against obesity and complications from insulin resistance (IR) [4, 5]. Recently, it has also been reported that irisin has anti-inflammatory, anti-oxidative, and anti-apoptotic properties, which play a significant role in the protection from many diseases, such as atherosclerosis and myocardial infarctions [5]. 
Hyperglycemia contributes to the formation of advanced glycation end products (AGEs), which are vital to the progression of diabetic micro- and macrovascular complications that occur when the receptors of AGE (RAGE) are bound [6]; however, soluble RAGE (sRAGE) inhibits AGES interaction with RAGE cell surfaces, thus attenuating the hazardous effects of AGES [7].

The aim of this study was to investigate the effect of irisin treatment on metabolic and platelet function, to explore the effect of irisin treatment on sRAGE, and to demonstrate the possible association between sRAGE and platelet function in experimentally induced T2DM in adult male albino rats.

\section{Methods}

\subsection{Ethical approval}

The study was approved by Institution Review Board (IRB) of the Faculty of Medicine, Zagazig University, Zagazig, Egypt (ZU-IRB\# 3758/25-5-2017).

\subsection{Animals}

This study was performed at the Physiology and Medical Biochemistry \& Molecular Biology Departments, Faculty of Medicine, Zagazig University, Zagazig, Egypt.

A total of 33 adult male albino rats weighing $200 \pm 15 \mathrm{~g}$ were obtained from the Animal House at the Faculty of Veterinary Medicine, Zagazig University, Zagazig, Egypt. The animals were kept in steel wire cages (5-6 animals/ cage) at the Animal House of Faculty of Medicine, Zagazig University, Zagazig, Egypt under hygienic conditions at room temperature with natural light/dark cycles and were fed standard chow with free access to food and water.

\subsection{Grouping}

After one week of acclimatization, animals were divided into two groups:

Group I (control; $n=11$ ) animals were fed the normal chow diet with $5 \%$ energy from fat, and total calorific values of $20 \mathrm{~kJ} / \mathrm{kg}$ [8]; and Group II (T2DM group; $n=22$ ). Group II rats were further divided into two subgroups: Group IIa (vehicle-treated diabetic group; $n=11$ ) was treated with saline; Group IIb (irisin-treated diabetic group; $n=11$ ) was treated with irisin, administered at $1 \mu \mathrm{g} / \mathrm{kg}$ daily for 14 days intra-peritoneally [9].

\subsection{Induction of diabetes}

The rats were injected subcutaneously with $230 \mathrm{mg} / \mathrm{kg}$ nicotinamide (NA). After $15 \mathrm{~min}$, diabetes was induced by subcutaneous injection of streptozotocin (STZ; $35 \mathrm{mg} / \mathrm{kg}$ ) in $10 \mathrm{mmol} / \mathrm{L}$, freshly prepared, ice-cold citrate buffer ( $\mathrm{pH} 4.5)$. A second dose of NA and STZ were administered $24 \mathrm{~h}$ later. After induction, the animals in this group were switched to a high fat diet (40\% energy from fat) [10]. A week later, rats with a fasting blood glucose (FBG) between 180 and $220 \mathrm{mg} / \mathrm{dL}$ were considered diabetic and included in the study [11]. All drugs were obtained from Sigma (St. Louis, MO, USA). The diet was obtained from the Animal House of Faculty of Medicine, Zagazig University, Zagazig, Egypt.

\subsection{Serum glucometabolic and platelet parameters}

Twenty-four hours after the last irisin injection, overnight fasted rats were weighed, then killed under ether anesthesia, and $1 \mathrm{ml}$ blood samples were collected in EDTA containing tubes. These samples were used immediately to determine platelet count, mean platelet volume (MPV), platelet distribution width (PDW), and plateletcrit using an automated cell counter (Benesphera, the Netherlands). Additional $3 \mathrm{ml}$ blood samples were collected in clean, plastic centrifuge tubes, and allowed to coagulate. Afterward, the serum was separated by centrifugation at $3000 \mathrm{rpm}$ for $15 \mathrm{~min}$. The separated serum was stored at $-20{ }^{\circ} \mathrm{C}$ until assayed for glucose using the enzymatic colorimetric method (Spinreact, Spain) [12]. Insulin levels were measured using rat insulin enzymelinked immunosorbent assay (ELISA) kits (BioSource, Europe S.A.-Rue de l'Industrie, 4-A- 1300 Nivelles-Belgium) [13].

Homeostasis model assessments of insulin resistance were calculated: $($ HOMA-IR $)=$ insulin $(\mu \mathrm{U} / \mathrm{ml}) \times$ glucose $(\mathrm{mg} / \mathrm{dl}) / 405$ [14]. sRAGE levels were measured using rat ELISA kits (Shanghai Sunred bioTechnology Co.,Ltd, Ca: 201-11-5822) [15]. Total cholesterol, triglyceride, and high-density lipoprotein (HDL) levels were measured using the colorimetric method (Spinreact, Spain) [12]. Low-density lipoproteins were calculated as follows: $\mathrm{LDL}=\mathrm{TC}-\mathrm{HDL}-(\mathrm{TG} / 5)$ [16]. Very low-density lipoproteins (VLDL) were calculated as follows: $\mathrm{VLDL}=\mathrm{TG} / 5$ [12].

\subsection{Statistical analysis}

The results of this study were expressed as mean $\pm \mathrm{SD}$. Data were analyzed using one-way ANOVA, followed by the Post hoc test (LSD) to test for differences between groups. Pearson correlations were also performed. Multiple linear regression analysis was performed with sRAGE as the dependent variable. $p<0.05$ was considered significant. The statistical analysis was performed using the SPSS program (version 18 for windows; SPSS Inc. Chicago, IL, USA).

\section{Results}

\subsection{Effect of irisin treatment on metabolic parameters}

There was a significant increase in the final body weights (BW) of both diabetic groups (IIa and IIb) compared to 
Table 1 Anthropometric and serum metabolic parameters in all groups

\begin{tabular}{|c|c|c|c|}
\hline & Group I & Group Ila & Group Ilb \\
\hline Initial BW (g) & $200.82 \pm 10.51$ & $200.36 \pm 9.53$ & $200.64 \pm 10.60$ \\
\hline Final BW (g) & $200.27 \pm 15.58$ & $307.54 \pm 33.54^{\mathrm{a}^{*}}$ & $285.45 \pm 27.06^{\mathrm{a}^{*}}$ \\
\hline $\mathrm{FBG}(\mathrm{mg} / \mathrm{dl})$ & $88.91 \pm 6.59$ & $249.27 \pm 23.82^{\mathrm{a}^{*}}$ & $148.36 \pm 14.68^{\mathrm{a}^{*} \mathrm{~b}^{*}}$ \\
\hline Insulin (mIU/ml) & $24.98 \pm 3.03$ & $37.37 \pm 7.86^{\mathrm{a} *}$ & $31.08 \pm 7.52^{\mathrm{a}^{*} b^{*}}$ \\
\hline HOMA-IR & $5.44 \pm 0.60$ & $22.81 \pm 4.31^{\mathrm{a} \#}$ & $11.28 \pm 2.83^{\mathrm{anb \#}}$ \\
\hline $\mathrm{TC}(\mathrm{mg} / \mathrm{dl})$ & $68.73 \pm 13.23$ & $109.00 \pm 17.58^{\mathrm{a} \#}$ & $85.27 \pm 9.80^{\mathrm{a}^{*} b^{*}}$ \\
\hline TG $(\mathrm{mg} / \mathrm{dl})$ & $44.73 \pm 7.17$ & $195.64 \pm 49.67^{\mathrm{a} \#}$ & $122.09 \pm 37.57^{\mathrm{a}^{* \mathrm{~b}^{*}}}$ \\
\hline $\mathrm{HDL}(\mathrm{mg} / \mathrm{dl})$ & $29.73 \pm 7.15$ & $22.36 \pm 4.98^{\mathrm{a}^{*}}$ & $30.00 \pm 8.08^{\mathrm{b} *}$ \\
\hline LDL (mg/dl) & $30.07 \pm 9.04$ & $47.53 \pm 12.36^{\mathrm{a}^{*}}$ & $30.84 \pm 7.83^{\mathrm{b}^{*}}$ \\
\hline $\operatorname{VLDL}(\mathrm{mg} / \mathrm{dl})$ & $8.95 \pm 1.43$ & $39.13 \pm 9.93^{\text {a\# }}$ & $24.42 \pm 7.51^{\mathrm{a} \# \mathrm{~b}^{*}}$ \\
\hline sRAGES (ng/ml) & $6.07 \pm 0.51$ & $5.40 \pm 0.77^{\mathrm{a}^{*}}$ & $6.02 \pm 0.53^{\mathrm{b}^{*}}$ \\
\hline
\end{tabular}

All data are expressed as mean $\pm S D$

${ }^{*} p<0.05$

$\# p<0.001$

a Significant compared to group I

${ }^{\text {b }}$ Significant compared to group lla

the control group $(p<0.05)$ but there was no significant difference in the BWs of the two groups $(p>0.05$; Table 1$)$. There was a significant increase in serum glucose, insulin and HOMA-IR in group (IIa) compared to the control group $(p<0.05)$. The irisin-treated diabetic rats (IIb) showed a significant reduction in the above-mentioned parameters compared to the diabetic group (IIa; $p<0.05$, $p<0.05, p<0.001$, respectively). Serum glucose, insulin, and HOMA-IR were significantly higher compared to the control $(p<0.05, p<0.05, p<0.001$, respectively; Table 1$)$.

The lipid profiles showed a significant increase in TC, TG, LDL, and VLDL in the diabetic groups (IIa and IIb) compared to the control group $(p<0.001, p<0.001$, $p<0.05, p<0.001$, respectively); however, these parameters were significantly decreased in group IIb after irisin treatment compared to group IIa $(p<0.05$; Table 1$)$. In addition, serum HDL showed a significant decrease in group IIa compared to the control $(p<0.05)$. HDL was significantly increased in group IIb compared to group IIa $(p<0.05)$, with no significant change compared to the control group $(p>0.05$; Table 1$)$.

\subsection{Effect of irisin treatment on SRAGE}

Serum sRAGE was significantly decreased in diabetic group IIa compared to the control group $(p<0.05)$. Group IIb displayed a significant increase in serum sRAGE $(p<0.05)$ compared to the diabetic group (IIa; $p<0.05)$, but the difference was not significant compared to the control group ( $p>0.05$; Fig. 1$)$.

\section{Serum sRAGE levels in all studied groups $(\mathrm{ng} / \mathrm{ml})$}

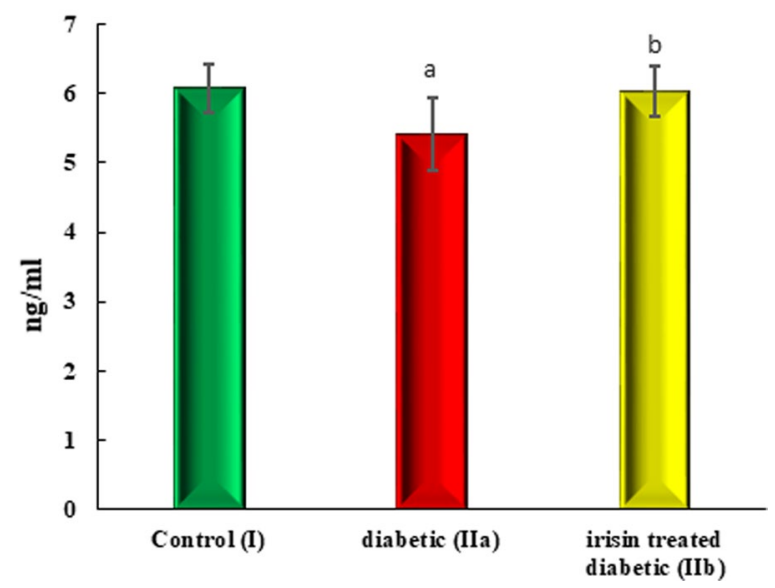

Fig. 1 Soluble Receptor of Advanced Glycation End Products (sRAGEs) levels in all studied groups. Data are expressed as mean \pm SD. ${ }^{\text {a: }}$ significant compared to group I; ${ }^{\text {b: }}$ significant compared to group lla

\subsection{Effect of irisin treatment on platelet function}

T2DM (group IIa) induced a significant increase in platelet count, MPV, PDW, and plateletcrit compared to the control group $(p<0.001, p<0.001, p<0.05$, and $p<0.001$, respectively). Intraperitoneal administration of irisin induced a significant reduction of all of these parameters compared to the untreated diabetic group (IIa; $p<0.05$ ). In contrast, platelet count, PDW, and plateletcrit were significantly higher after irisin treatment in group IIb in comparison to the control group $(p<0.01, p<0.05$, $p<0.05$, respectively). No significant change in MPV was found between group IIb and the control $(p>0.05$; Table 2).

\subsection{Correlation and linear regression analysis of sRAGE with glucometabolic and platelet parameters}

sRAGE had a significant negative correlation with final BW $(p<0.05)$, FBG $(p<0.01)$, HOMA-IR $(p<0.05)$, TC, TG, LDL, and VLDL $(p<0.01)$. There was no significant correlation between sRAGE and either insulin or HDL levels (Table 3). Additionally, serum sRAGE displayed a significant negative correlation with platelet count $(p<0.05)$, MPV $(p<0.001)$, PDW $(p<0.01)$, and PCT $(p<0.001$; Table 3$)$.

The results of the linear regression analysis showed a significant linear regression with $85 \%$ predictive value of MPV to the change in the serum level of sRAGE ( $\beta$ coefficient $=0.851, p<0.05)$; however, none of the other independent variables showed significant predictive value for sRAGE (Table 4). 
Table 2 Blood platelet parameters in all groups

\begin{tabular}{|c|c|c|c|}
\hline & Group I & Group Ila & Group IIb \\
\hline Platelet count $\times 10^{3} \mathrm{cell} / \mu \mathrm{L}$ & $644.82 \pm 87.86$ & $935.73 \pm 100.45^{\text {a\# }}$ & $813.27 \pm 108.11^{a \vdots b^{*}}$ \\
\hline MPV (FI) & $7.70 \pm 0.18$ & $9.20 \pm 0.56^{\mathrm{a \#}}$ & $7.71 \pm 0.47^{b^{*}}$ \\
\hline PDW (\%) & $36.20 \pm 1.66$ & $39.48 \pm 1.54^{\mathrm{a}^{*}}$ & $37.70 \pm 1.50^{a^{*} b^{*}}$ \\
\hline Plateletcrit (\%) & $0.52 \pm 0.06$ & $0.88 \pm 0.11$ a\# & $0.62 \pm 0.10^{a^{*} b^{*}}$ \\
\hline
\end{tabular}

Data are expressed as mean $\pm S D$

${ }^{*} p<0.05$

${ }^{\$} p<0.01$

\# $p<0.001$

${ }^{\text {a }}$ Significant compared to group I

${ }^{\mathrm{b}}$ Significant compared to group Ila, $p<0.05$

Table 3 Pearson correlation of sRAGE with glucometabolic and platelet parameters

\begin{tabular}{lcc}
\hline & $r$ & $P$ value \\
\hline Final body weight & -0.398 & $0.022^{*}$ \\
FBG & -0.558 & $0.001^{*}$ \\
Insulin & 0.057 & 0.753 \\
HOMA-IR & -0.417 & $0.016^{*}$ \\
Platelets count & -0.530 & $0.002^{* *}$ \\
MPV & -0.699 & $<0.001^{* *}$ \\
PDWs & -0.459 & $0.007^{*}$ \\
PCT & -0.608 & $<0.001^{* *}$ \\
TC & -0.512 & $0.002^{*}$ \\
TG & -0.459 & $0.007^{*}$ \\
LDL & -0.524 & $0.002^{*}$ \\
VLDL & -0.459 & $0.007^{*}$ \\
HDL & 0.288 & 0.104 \\
\hline
\end{tabular}

*Significant level at $p<0.05$

**Highly significant level at $p<0.001$

Table 4 Multiple linear regressions of SRAGE with the dependent variable

\begin{tabular}{lcc}
\hline Independent variables & $\boldsymbol{\beta}$ coefficient & $\boldsymbol{p}$ value \\
\hline Final body weight & 0.103 & 0.651 \\
FBG & -0.540 & 0.382 \\
HOMA-IR & 0.738 & 0.068 \\
Platelets count & -0.010 & 0.972 \\
MPV & -0.851 & $0.040^{*}$ \\
PDWs & -0.077 & 0.768 \\
PCT & 0.105 & 0.812 \\
TC & 0.279 & 0.557 \\
LDL & -0.175 & 0.662 \\
VLDL & -0.220 & 0.647 \\
$F$ value of regression & 9.598 & \\
$p$ value & $0.023^{*}$ &
\end{tabular}

*Significant level at $p<0.05$

\section{Discussion}

RAGE and sRAGE are involved in DM-related disorders. sRAGE is composed of two components: the endogenously secretory form which is the real receptor and the membrane-cleaved form which is an inflammatory marker [17].

In this study, STZ displays cytotoxic action caused by increases in the production of reactive oxygen species (ROS) by pancreatic $\beta$-cells, which induces DM. Additionally, the combination of high fat diet (HFD) with STZ has been reported to induce IR and hyperglycemia [18]. Nicotinamide has been shown to mediate a partial protection against cellular damage induced by STZ [19]; thus, this animal model mimics human T2DM with IR $[10,20]$.

We found that the body weights in the diabetes group were significantly increased compared to the control group. This is in line with the findings of Veerapur et al. [21]. Additionally, the intraperitoneal administration of STZ significantly elevated FBG levels, with a significant increase in serum insulin levels, and HOMA-IR, which has also been reported previously [22, 23].

Our results also showed that irisin administration caused a significant reduction in serum glucose and insulin levels in STZ diabetic rats, which agrees with Liu et al. [24], who explained that by the promotion of $\beta$ cell proliferation. Irisin enhances glucose uptake and inhibits gluconeogenesis, thus leading to improved glucose utilization in T2DM rats [25]. These effects occur via activation of the $5^{\prime}$ adenosine monophosphate-activated protein kinase (AMPK) signaling pathway, and acetylCoA-carboxylase in hepatic cells, an effect that plays a significant role in cellular energy homeostasis [26].

We also found a significant increase in TC, TG, and LDL-C in the untreated, diabetic group compared to the control. These results are in line with those of other investigators [22, 27]. Irisin administration resulted in a significant decrease of TC and TG in the STZ diabetic 
rats. Similar results also reported that irisin administration decreased plasma TC and TG levels, suggesting that irisin improves energy metabolism in adipose tissue [2].

The platelet parameters showed a significant increase in platelet count, MPV, PDW, and PCT in the diabetic group compared to the control group, which has also been previously noted [27]. Irisin treatment significantly reduced these parameters compared to the untreated diabetic group. Increased MPV is an indicator of platelet size in T2DM and is attributed to the osmotic swelling of platelets caused by high levels of glucose metabolites [2]. This finding is consistent with other studies that have also reported increased MPV in diabetic patients compared to non-diabetic controls [2, 28]. In diabetic patients with atherothrombotic vascular complications, MPV could also be elevated as result of the compensatory production of reticulated platelets due to the increased consumption of small platelets [2]. The increased PDW was attributed to enhanced platelet production that caused qualitative changes, such as the production of different sized platelets and activated platelets that change from a discoid to a spherical shape with pseudopodia formation, leading to a change in PDW [29]. These findings correspond to those of Alhadas et al. [27] and Dalamaga et al. [30], who noticed that PDW was higher in diabetic patients compared to non-diabetics. Increased PCT could be caused by the increased platelet size and reactivity in type 2 diabetic patients, as these can lead to increases in platelet mass, thus resulting in increased PCT [27].

In DM, the high levels of AGE and RAGE ligands can induce pro-inflammatory and pro-thrombotic states, endothelial cells dysfunction, and vascular leakage [31]. In addition, many factors interact to cause platelet hyperreactivity, such as hyperglycemia and hyperlipidemia, IR, overexpression of inflammatory and oxidant stress mediators, glycoprotein receptors, and growth factors [2]. Hyperglycemia decreases platelet membrane fluidity, thus increasing platelet activation [32]. Dyslipidemia induces a pro-thrombotic state, which is associated with platelet hyper-reactivity [33]. A decreased platelet count in diabetic type 2 patients compared to non-diabetic patients, and the presence of other factors affecting platelet counts, such as the mean platelet survival, platelet production, and their turnover rate has been previously suggested [34], which disagrees with our results. This difference could be related to differences in the genetics, species, or disease duration in the respective studies.

The primary finding of this study was the significant decrease of platelet parameters in the irisin-treated group compared to the untreated diabetic group. This finding is attributed to irisin's effect on blood glucose, as evidenced by the significant reductions in serum glucose, insulin, and HOMA-IR, accompanied by significant improvements in lipid metabolism, which potentially plays a role in the reduction of platelet hyperactivity.

Also, we found a significant decrease in sRAGE levels in the diabetic group compared to the control group; however, irisin treatment in the treated diabetic group significantly increased sRAGE levels compared to the diabetic group.

Irisin is a promising key player in metabolic diseases and other diseases which improve with exercise [35]. Irisin has anti-inflammatory properties that inhibit the expression and release of inflammatory mediators [6]. Li et al. [6] found that patients with endothelial dysfunction had low irisin levels, which were negatively correlated with AGE [6]. Moreover, irisin decreased the atherosclerotic plaque area and inflammatory response in STZinduced diabetic apolipoprotein E-knockout mice [36]. Irisin reduced oxidative stress, inhibited glucose-induced apoptosis, and upregulated the proliferation and angiogenesis of human endothelial cell lines [37, 38].

We found a significant negative correlation between sRAGE and platelet count, MPV, PDWs, and PCT. In addition, linear regression analysis demonstrated that MPV had a significant predictive value for the change in serum sRAGE. Our results agree with those of Fujisawa et al. [42], who reported that sRAGE was negatively associated with metabolic syndrome, and that its low level was associated with increased cardiovascular risk factors in this condition. Interestingly, the significant negative correlation between sRAGE and serum FBG, HOMAIR, TC, TG, LDL, and VLDL levels in this study supports these findings [39]. sRAGE has anti-inflammatory effects by blocking the interactions between AGEs and membrane-bound RAGE, and by preventing the effects of AGEs [40, 41]. Thus, increased sRAGE prevents T2DMinduced endothelial cell injury and inhibits the hyperactivation of platelets [42].

\section{Conclusions}

It could be deduced from our results that circulating serum sRAGE levels could represent a novel biomarker of vascular complications. The treatment of STZ-induced type 2 diabetic rats with I.P. irisin for 14 days improved platelet profile and metabolic status. Moreover, mean platelet volume is an independent predictive factor for serum sRAGE level in diabetic rats. These results suggest that the treatment with irisin might be a novel mechanism for the beneficial effects in patients with type 2 diabetes.

\subsection{Limitations and recommendations}

The data from this study on the effects of irisin on the AGE-RAGE axis are limited. Further studies are needed 
to understand the clinical significance of irisin supplementation in the context of RAGE and sRAGE regulation. Therapeutic antagonism of RAGE-dependent signaling could provide a new target for prevention of diabetes mellitus complications, particularly those associated with the increased risk of thrombosis.

\begin{abstract}
Abbreviations
SRAGE: Soluble receptor of advanced glycation end products; T2DM: Type 2 diabetes mellitus; FNDC5: Fibronectin type III domain-containing protein 5; PPARY: Peroxisome proliferator-activated receptor $\gamma$; PGC-1a: Peroxisome proliferator-activated receptor $\gamma$ (PPAR $\gamma$ ) co-activator-1 $\alpha$; IR: Insulin resistance; AGEs: Advanced glycation end products; STZ: Streptozotocin; FBG: Fasting blood glucose; MPV: Mean platelet volume; PDW: Platelet distribution width; LDL: Low-density lipoprotein; VLDL:Very low-density lipoprotein; TG: Triglyceride; TC: Total cholesterol; BW: Body weight; UCP-1: Uncoupler Protein-1; AMPK: $5^{\prime}$ Adenosine monophosphate-activated protein kinase; PDGF: Platelet-derived growth factor; VEGF: Vascular endothelial growth factor; eNOS: Endothelial NO synthase.
\end{abstract}

\section{Acknowledgements}

Not applicable.

\section{Authors' contributions}

SWM and MMH designed and directed the project. HES, TE, SH and NFE performed the experiments and analyzed the data. $\mathrm{MMH}$ and $\mathrm{SH}$ wrote the manuscript. All authors have read and approved the manuscript.

\section{Funding}

None.

\section{Availability of data and materials}

The data that support the findings of this study are available from the corresponding author upon reasonable request.

\section{Declarations}

\section{Ethics approval and consent to participate}

The study was approved by Institution Review Board, Faculty of Medicine, Zagazig University (ZU-IRB\# 3758/25-5-2017). All animal experiments were performed according to Egyptian Animal Welfare laws and were carried out according to the approved animal research protocol. A written informed consent was obtained from the Animal House of Faculty of Veterinary Medicine, Zagazig University-the owner of the animals- to use the animals in our study.

\section{Consent for publication}

Not applicable.

\section{Competing interests}

The authors declare that they have no competing interests.

\section{Author details}

'Physiology Department, Faculty of Medicine, Zagazig University, Zagazig, Egypt. ${ }^{2}$ College of Medicine, Mutah University, Mutah, Jordan. ${ }^{3}$ Clinical Pathology Department, Faculty of Medicine, Zagazig University, Zagazig, Egypt. ${ }^{4} \mathrm{Fac}-$ ulty of Medicine, Zawia University, Az-Zāwiyah, Libya. ${ }^{5}$ Medical Biochemistry and Molecular Biology, Faculty of Medicine, Zagazig University, Zagazig, Egypt.

Received: 20 May 2021 Accepted: 13 September 2021

Published online: 07 October 2021

\section{References}

1. De Rosa S, Arcidiacono B, Chiefari E, Brunetti A, Indolfi C, Foti DP (2018) Type 2 diabetes mellitus and cardiovascular disease: genetic and epigenetic links. Front Endocrinol 9:2
2. Tejeswini V, Premalatha P, Krishnamacharyulu PAV (2016) Role of mean platelet volume in individuals with type II diabetes mellitus. J Clin Pathol Foren Med 7(1):1-6

3. Boström P, Wu J, Jedrychowski MP, Korde A, Ye L, Lo JC, Rasbach KA, Boström EA, Choi JH, Long JZ, Kajimura S (2012) A PGC1-a-dependent myokine that drives brown-fat-like development of white fat and thermogenesis. Nature 481(7382):463-468

4. Guilford BL, Parson JC, Grote CW, Vick SN, Ryals JM, Wright DE (2017) Increased FNDC 5 is associated with insulin resistance in high fat-fed mice. Physiol Rep 5(13):e13319

5. Askari H, Rajani SF, Poorebrahim M, Haghi-Aminjan H, Raeis-Abdollahi E, Abdollahi M (2018) A glance at the therapeutic potential of irisin against diseases involving inflammation, oxidative stress, and apoptosis: an introductory review. Pharmacol Res 129:44-55

6. Li Z, Wang G, Zhu YJ, Li CG, Tang YZ, Jiang ZH, Yang M, Ni CL, Chen LM, Niu WY (2017) The relationship between circulating irisin levels and tissues AGE accumulation in type 2 diabetes patients. Biosci Rep 37(3):20171213

7. Maillard-Lefebvre H, Boulanger E, Daroux M, Gaxatte C, Hudson BI, Lambert M (2009) Soluble receptor for advanced glycation end products: a new biomarker in diagnosis and prognosis of chronic inflammatory diseases. Rheumatology 48(10):1190-1196

8. Liu Z, Li W, Li X, Zhang M, Chen L, Zheng YN, Sun GZ, Ruan CC (2013) Antidiabetic effects of malonyl ginsenosides from Panax ginseng on type 2 diabetic rats induced by high-fat diet and streptozotocin. J Ethnopharmacol 145(1):233-240

9. Fu J, Han Y, Wang J, Liu Y, Zheng S, Zhou L, Jose PA, Zeng C (2016) Irisin lowers blood pressure by improvement of endothelial dysfunction via AMPK-Akt-eNOS-NO pathway in the spontaneously hypertensive Rat. J Am Heart Assoc 5(11):e003433

10. Wang RY, Huang JH, Hsu GSW, Lin WT, Lu YF (2017) Hypoglycemic and antioxidative effects of Glossogyne tenuifolia on streptozotocin-nicotinamide-induced diabetic rats. Am J Plant Sci 8(5):1170-1181

11. Nayak Y, Hillemane V, Daroji VK, Jayashree BS, Unnikrishnan MK (2014) Antidiabetic activity of benzopyrone analogues in nicotinamide-Streptozotocin induced type 2 diabetes in rats. Sci World J

12. Tietz NW, Ash KO (1995) Clinical guide to laboratory tests. Clin Chem $41(10): 1548-1548$

13. Temple R, Clark PMS, Hales CN (1992) Measurement of insulin secretion in type 2 diabetes: problems and pitfalls. Diabet Med 9(6):503-512

14. Matthews DR, Hosker JP, Rudenski AS, Naylor BA, Treacher DF, Turner RC (1985) Homeostasis model assessment: insulin resistance and $\beta$-cell function from fasting plasma glucose and insulin concentrations in man. Diabetologia 28(7):412-419

15. Falcone C, Emanuele E, D'Angelo A, Buzzi MP, Belvito C, Cuccia M, Geroldi D (2005) Plasma levels of soluble receptor for advanced glycation end products and coronary artery disease in nondiabetic men. Arterioscler Thromb Vasc Biol 25(5):1032-1037

16. Friedewald WT, Levy RI, Fredrickson DS (1972) Estimation of the concentration of low-density lipoprotein cholesterol in plasma, without use of the preparative ultracentrifuge. Clin Chem 18(6):499-502

17. Egana-Gorrono L, Lopez-Diez R, Yepuri G, Ramirez LS, Reverdatto S, Gugger PF, Shekhtman A, Ramasamy R, Schmidt AM (2020) Receptor for advanced glycation end products (RAGE) and mechanisms and therapeutic opportunities in diabetes and cardiovascular disease: insights from human subjects and animal models. Front Cardiovasc Med 7:37

18. Das UN (2017) Is there a role for bioactive lipids in the pathobiology of diabetes mellitus? Front Endocrinol 8:182

19. Kishore L, Kajal A, Kaur N (2017) Role of nicotinamide in streptozotocin induced diabetes in animal models. J Endocrinol Thyroid Res 2(1):1-4

20. Zhuo J, Zeng Q, Cai D, Zeng X, Chen Y, Gan H, Huang X, Yao N, Huang D, Zhang C (2018) Evaluation of type 2 diabetic mellitus animal models via interactions between insulin and mitogen-activated protein kinase signaling pathways induced by a high fat and sugar diet and streptozotocin. Mol Med Rep 17(4):5132-5142

21. Veerapur VP, Prabhakar KR, Thippeswamy BS, Bansal P, Srinivasan KK, Unnikrishnan MK (2012) Antidiabetic effect of Ficus racemosa Linn. stem bark in high-fat diet and low-dose streptozotocin-induced type 2 diabetic rats: a mechanistic study. Food Chem 132(1):186-193 
22. Gamal MM, Tork OM, Eshra MA, Magdy S, Rashed LA (2016) Role of endogenous irisin, a novel myokine, in cognitive functions and insulin sensitivity in exercised diabetic rats. Kasr Al Ainy Med J 22(3):136

23. Xie R, Zhang H, Wang XZ, Yang XZ, Wu SN, Wang HG, Shen P, Ma TH (2017) The protective effect of betulinic acid (BA) diabetic nephropathy on streptozotocin (STZ)-induced diabetic rats. Food Funct 8(1):299-306

24. Liu S, Du F, Li X, Wang M, Duan R, Zhang J, Wu Y, Zhang Q (2017) Effects and underlying mechanisms of irisin on the proliferation and apoptosis of pancreatic $\beta$ cells. PLoS ONE 12(4):e0175498

25. Gizaw M, Anandakumar P, Debela T (2017) A review on the role of irisin in insulin resistance and type 2 diabetes mellitus. J Pharmacopuncture 20(4):235

26. So WY, Leung PS (2016) Irisin ameliorates hepatic glucose/lipid metabolism and enhances cell survival in insulin-resistant human HepG2 cells through adenosine monophosphate-activated protein kinase signaling Int J Biochem Cell Biol 78:237-247

27. Alhadas KR, Santos SN, Freitas MMS, Viana SMS, Ribeiro LC, Costa MB (2016) Are platelet indices useful in the evaluation of type 2 diabetic patients? Jornal Brasileiro de Patologia e Medicina Laboratorial 52(2):96-102

28. Kodiatte TA, Manikyam UK, Rao SB, Jagadish TM, Reddy M, Lingaiah HKM, Lakshmaiah V (2012) Mean platelet volume in type 2 diabetes mellitus. J Lab Phys 4(1):5

29. Shah B, Sha D, Xie D, Mohler ER, Berger JS (2012) The relationship between diabetes, metabolic syndrome, and platelet activity as measured by mean platelet volume: the National Health And Nutrition Examination Survey, 1999-2004. Diabetes Care 35(5):1074-1078

30. Vagdatli E, Gounari E, Lazaridou E, Katsibourlia E, Tsikopoulou F, Labrianou I (2010) Platelet distribution width: a simple, practical and specific marker of activation of coagulation. Hippokratia 14(1):28

31. Dozio E, Sitzia C, Pistelli L, Cardani R, Rigolini R, Ranucci M, Corsi Romanelli MM (2020) Soluble receptor for advanced glycation end products and its forms in COVID-19 patients with and without diabetes mellitus: a pilot study on their role as disease biomarkers. J Clin Med 9(11):3785

32. Jindal S, Gupta S, Gupta R, Kakkar A, Singh HV, Gupta K, Singh S (2011) Platelet indices in diabetes mellitus: indicators of diabetic microvascular complications. Hematology 16(2):86-89

33. Kakouros N, Rade JJ, Kourliouros A, Resar JR (2011) Platelet function in patients with diabetes mellitus: from a theoretical to a practical perspective. Int J Endocrinol
34. Kaur R, Kaur M, Singh J (2018) Endothelial dysfunction and platelet hyperactivity in type 2 diabetes mellitus: molecular insights and therapeutic strategies. Cardiovasc Diabetol 17(1):1-17

35. Seo DY, Bae JH, Kim TN, Kwak HB, Kha PT, Han J (2020) Exercise-induced circulating irisin level is correlated with improved cardiac function in rats. Int J Environ Res Public Health 17:3863

36. Mahajan N, Dhawan V (2013) Receptor for advanced glycation end products (RAGE) in vascular and inflammatory diseases. Int J Cardiol 168(3):1788-1794

37. Mazur-Bialy Al, Pocheć E, Zarawski M (2017) Anti-inflammatory properties of irisin, mediator of physical activity, are connected with TLR4/MyD88 signaling pathway activation. Int J Mol Sci 18(4):701

38. Lu J, Xiang G, Liu M, Mei W, Xiang L, Dong J (2015) Irisin protects against endothelial injury and ameliorates atherosclerosis in apolipoprotein E-Null diabetic mice. Atherosclerosis 243(2):438-448

39. Wu F, Song $H$, Zhang $Y$, Zhang $Y$, Mu Q, Jiang M, Wang F, Zhang W, Li L, $\mathrm{Li} \mathrm{H}$, Wang $Y(2015)$ Irisin induces angiogenesis in human umbilical vein endothelial cells in vitro and in zebrafish embryos in vivo via activation of the ERK signaling pathway. PLOS ONE 10(8):e0134662

40. Deng $X$, Huang W, Peng J, Zhu TT, Sun $X L$, Zhou $X Y$, Yang $H$, Xiong JF, He HQ, Xu YH, He YZ (2018) Irisin alleviates advanced glycation end products-induced inflammation and endothelial dysfunction via inhibiting ROS-NLRP3 inflammasome signaling. Inflammation 41(1):260-275

41. Scavello F, Zeni F, Milano G, Macrì F, Castiglione S, Zuccolo E, Scopece A, Pezone G, Tedesco CC, Nigro P, Degani G, Gambini E, Veglia F, Popolo L, Pompilio G, Colombo GI, Bianchi ME, Raucci A (2021) Soluble Receptor for advanced glycation end-products regulates age-associated cardiac fibrosis. Int J Biol Sci 17(10):2399-2416

42. Fujisawa K, Katakami N, Kaneto H, Naka T, Takahara M, Sakamoto F, Irie Y, Miyashita K, Kubo F, Yasuda T, Matsuoka TA (2013) Circulating soluble RAGE as a predictive biomarker of cardiovascular event risk in patients with type 2 diabetes. Atherosclerosis 227(2):425-428

\section{Publisher's Note}

Springer Nature remains neutral with regard to jurisdictional claims in published maps and institutional affiliations.

\section{Submit your manuscript to a SpringerOpen ${ }^{\circ}$ journal and benefit from:}

- Convenient online submission

- Rigorous peer review

- Open access: articles freely available online

- High visibility within the field

Retaining the copyright to your article

Submit your next manuscript at springeropen.com 